\title{
Review:
}

\section{The Origin, Physicochemical Properties, and Removal Technology of Metallic Porphyrins from Crude Oils}

\author{
Jumina $^{1^{\star}}$, Yehezkiel Steven Kurniawan ${ }^{1,2}$, Dwi Siswanta ${ }^{1}$, Bambang Purwono ${ }^{1}$, Abdul Karim \\ Zulkarnain $^{3}$, Agustinus Winarno ${ }^{4}$, Joko Waluyo ${ }^{5}$, and Johan Syafri Mahathir Ahmad ${ }^{6}$ \\ ${ }^{1}$ Department of Chemistry, Faculty of Mathematics and Natural Sciences, Universitas Gadjah Mada, \\ Sekip Utara, Yogyakarta 55281, Indonesia \\ ${ }^{2}$ Ma Chung Research Center for Photosynthetic Pigments, Universitas Ma Chung, Malang 65151, Indonesia \\ ${ }^{3}$ Department of Pharmaceutical Technology, Faculty of Pharmacy, Universitas Gadjah Mada, \\ Sekip Utara, Yogyakarta 55281, Indonesia \\ ${ }^{4}$ Department of Mechanical Engineering, Vocational College, Universitas Gadjah Mada, \\ Sekip Utara, Yogyakarta 55281, Indonesia \\ ${ }^{5}$ Department of Mechanical and Industrial Engineering, Faculty of Engineering, Universitas Gadjah Mada, \\ Jl. Grafika No. 2 UGM Campus, Yogyakarta 55281, Indonesia \\ ${ }^{6}$ Department of Civil and Environmental Engineering, Faculty of Engineering, Universitas Gadjah Mada, \\ Jl. Grafika No. 2 UGM Campus, Yogyakarta 55281, Indonesia
}

\section{*Corresponding author: \\ tel: $+62-2745-45188$ \\ email:jumina@ugm.ac.id \\ Received: December 24, 2020 \\ Accepted: March 29, 2021}

DOI: $10.22146 / \mathrm{ijc} .62521$

\begin{abstract}
Crude oil is an indispensable energy feedstock for daily activities, although some amounts of metallic porphyrins components with undesired characteristics have been identified. These constituents are assumed to originate from the geochemical process of chlorophyll and heme derivatives. In addition, their chemical structures have been thoroughly characterized using spectroscopy techniques, while several analytical methods were adopted in the detection and concentration quantification in the crude oils. The metallic porphyrins have several demerits, including the deactivation of used catalysts, contamination of the treated petrochemical products, and corrosion of the industrial equipment. Also, the removal process is considered challenging due to the strong interaction with the asphaltene fraction of crude oil. This review article, therefore, provides brief information on the origin, physicochemical properties, and possible removal technology of metallic porphyrins from crude oil samples. Besides, a better understanding of chemistry contributes a useful insight towards the development and establishment of better futuristic processing technology.
\end{abstract}

Keywords: crude oil; metallic porphyrin; origin; property; removal

\section{- INTRODUCTION}

Despite the extensive research on renewable energy, crude oil remains an indispensable energy feedstock [14]. This is attributed to the limited amount of industrial processes implicated in serious demerits, including expensive upfront cost, geographic mal-distribution, natural intermittent supply, and others. In contrast, crude oil-based chemical materials are well established worldwide. Therefore, some industries prefer maintaining fossil-based technological systems against establishing new and high-cost technologies [5].

Crude oil is generally defined as a fuel liquid produced through long-time geological activities involving high temperature and pressure in oil reservoirs associated with sedimentary rocks and

Jumina et al. 
situated beneath earth's surface piles [6]. This natural resource comprises light and heavy hydrocarbon fractions with other impurities, including oxygenated-, nitrogenated-, and sulphated-compounds, alongside trace metals [7]. The respective compound composition varies appreciably across the reservoirs, and crude oil also contains paraffin (alkanes), naphthenes (cycloalkanes), as well as aromatic compounds [8]. In addition, some components have been separated through a fractionation distillation process for commercial applications, and further actions in the form of thermal cracking, catalytic reforming, isomerization, and hydrodealkylation processes are possibly required to attain the product market requirement [9]. Therefore, impurity elimination is pivotal to obtain products with high-purity [10].

The oxygenated-, nitrogenated- and sulphatedcompounds present are easily removed through the absorption and hydrocracking processes [11]. However, trace metal removal is difficult in a simple process, due to the high solubility and the poisonous impact of catalysis techniques [12]. Furthermore, the amount present was reportedly dominated by metallic porphyrins [6], and special attention is attributed to these constituents over the past several years. This is due to the high poison potential and ability to deactivate catalysts used during petrochemical processes [11]. Hence, further information on the intrinsic chemical nature is required. This review article involves the assessment of data on the metallic porphyrin's origin, its chemical structure, and physicochemical properties. Also, the removal process from crude oils is briefly discussed to provide chemists and engineers working on crude oil processing with essential knowledge.

\section{- ORIGIN OF METALLIC PORPHYRINS}

Treibs [13] firstly discovered metallic porphyrins as "molecular fossils" from crude oil samples in 1934, and further investigations have gained significant interest. This has been identified as the predominant trace metal, and Table 1 lists others present in Venezuelan crude oil, comprising vanadium and nickel at 440-617 and 70-94 $\mathrm{mg} \mathrm{L} \mathrm{L}^{-1}$, respectively, which is 600 times higher than the others [6]. Conversely, vanadium $\left(160 \mathrm{mg} \mathrm{L}^{-1}\right)$ and nickel
(80 $\mathrm{mg} \mathrm{L}^{-1}$ ) metals in the lithosphere are not as abundant as iron $\left(50,000 \mathrm{mg} \mathrm{L}^{-1}\right)$ and calcium $\left(40,000 \mathrm{mg} \mathrm{L}^{-1}\right)$. Therefore, some extensive studies were conducted to evaluate the reason for the much higher concentration of vanadyl-porphyrins or nickel-porphyrins in crude oil compared to others.

Furimsky [6] attributed the abundant quantity of vanadium and nickel to the intrinsic high reducibility of the mineral form. This property impacts greater stability on metallic species and ensures the formation of tighter bonds to the core porphyrin framework. This hypothesis suggests all metallic species are generated from the reduction of corresponding metallic oxides by hydrogen gas (Eq. (1)).

$$
\mathrm{M}_{\mathrm{x}} \mathrm{O}_{\mathrm{y}}(\mathrm{s})+\mathrm{yH}_{2}(\mathrm{~g}) \rightarrow \mathrm{xM}(\mathrm{s})+\mathrm{yH}_{2} \mathrm{O}(\mathrm{g})
$$

The reduction reaction of $\mathrm{V}_{2} \mathrm{O}_{5}$ to $\mathrm{V}$ species is not spontaneous $\left(\Delta \mathrm{G}_{300 \mathrm{~K}}=+33.4 \mathrm{~kJ} \mathrm{~mol}^{-1}\right)$ while $\mathrm{V}_{2} \mathrm{O}_{5}$ to vanadyl $(\mathrm{V}=\mathrm{O})$ species is highly favorable $\left(\Delta \mathrm{G}_{300 \mathrm{~K}}=-8.3\right.$ $\mathrm{kJ} \mathrm{mol}^{-1}$ ). Similarly, the reduction of $\mathrm{NiO}$ to $\mathrm{Ni}$ species is also spontaneous $\left(\Delta \mathrm{G}_{300 \mathrm{~K}}=-4.0 \mathrm{~kJ} \mathrm{~mol}^{-1}\right)$, while $\mathrm{FeO}$, $\mathrm{CaO}$, or $\mathrm{CuO}$ are considered as unfavorable, due to the positive Gibbs energy produced, at $+5.4,+227$, and +24.2 $\mathrm{kJ} \mathrm{mol}^{-1}$, respectively [6]. Therefore, Furimsky stipulated the significance of much higher vanadyl and nickel metal concentrations in metallic porphyrins, compared to iron, calcium, and copper metals in crude oils.

Treibs [13] proposed plausible evolution reactions required to form metallic porphyrins in crude oil. This includes the production from chlorophyll compounds in plants and heme compounds in animals [14], as shown in Fig. 1. Furthermore, the chlorophylls from plants are

Table 1. Trace metal composition in the Venezuelan crude oil sample [6]

\begin{tabular}{cc}
\hline Metals & Concentration $\left(\mathrm{mg} \mathrm{L}^{-1}\right)$ \\
\hline $\mathrm{Fe}$ & $4.0-7.5$ \\
$\mathrm{Ca}$ & $11-57$ \\
$\mathrm{Mg}$ & $1.0-10$ \\
$\mathrm{~V}$ & $440-617$ \\
$\mathrm{Ni}$ & $70-94$ \\
$\mathrm{Cu}$ & $2.0-17$ \\
$\mathrm{Mo}$ & $3.0-22$ \\
$\mathrm{Cd}$ & $1.0-5.0$ \\
$\mathrm{Zn}$ & $1.0-12$ \\
\hline
\end{tabular}



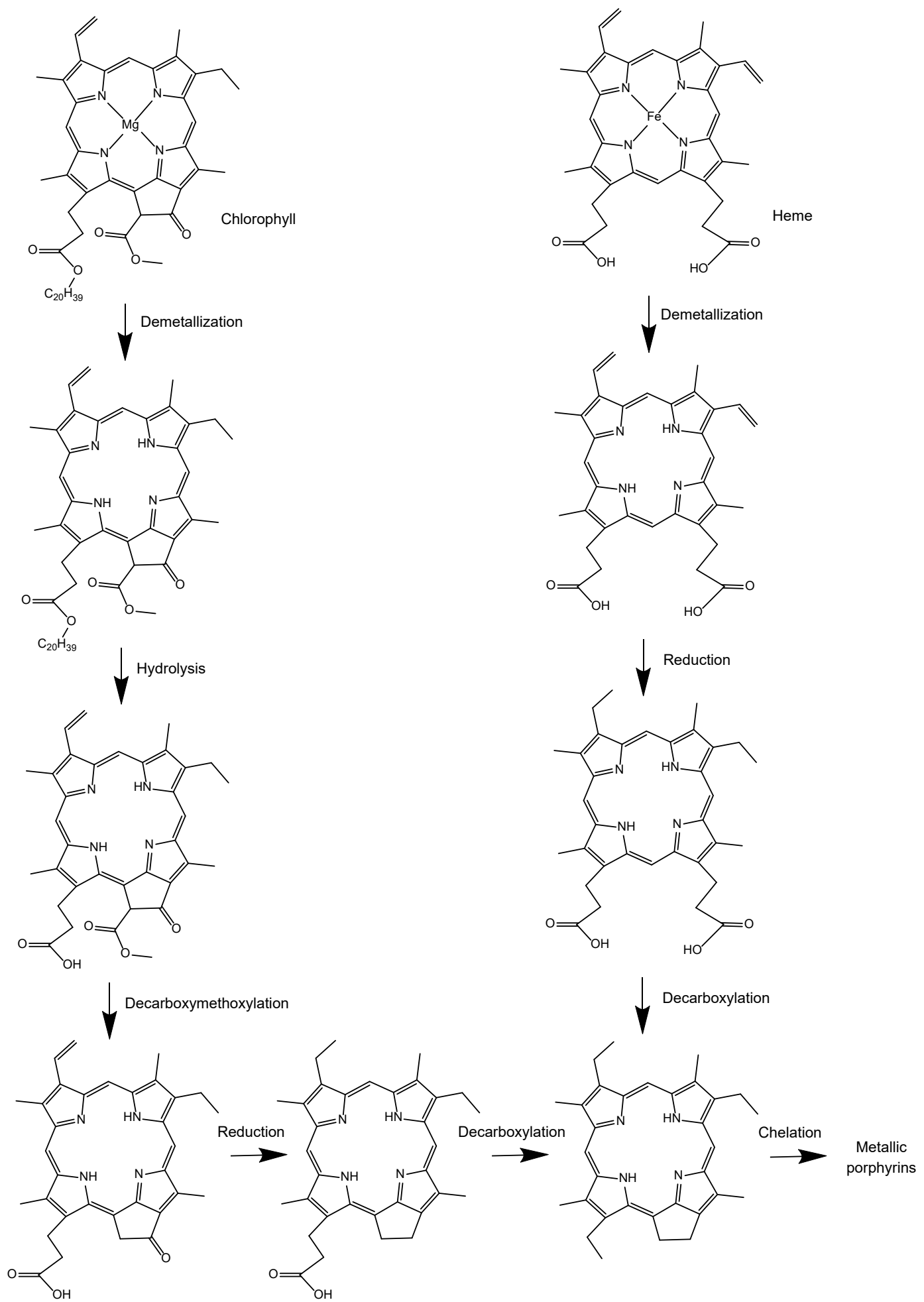

Fig 1. Schematic evolution reactions of chlorophyll and heme compounds to form metallic porphyrins

determined to engage in demetallization reactions and consequently release $\mathrm{Mg}^{2+}$ ions. These $\mathrm{Mg}^{2+}$-free porphyrins then engage in hydrolysis, decarbomethoxylation, reduction, and decarboxylation reactions to produce the "free" ligand. The high reducibility of vanadyl and nickel facilitates the 
chelation required in the formation of stable metal complexes. Moreover, heme compounds are converted to $\mathrm{Fe}^{2+}$-free porphyrins through a demetallization reaction and further treated with reduction and decarboxylation processes. The vanadyl and nickel species were finally complexed with the porphyrin ligand to form metallic porphyrins [14].

Castillo and Vargas [15] performed further studies by investigating the occlusion characteristics of metallic porphyrins during asphaltene aggregation. Consequently, either vanadyl- or nickel-porphyrin was predominant in the asphaltene fraction of crude oil [16]. Therefore, the combination phenomenon and the respective physicochemical properties were evaluated using UV-Vis spectroscopy. The asphaltene aggregation degree was examined at $350 \mathrm{~nm}$, while the metallic porphyrin electronic properties were evaluated based on the Soret signal at $400-410 \mathrm{~nm}$. Furthermore, the results obtained showed the trapping of more than 50\% metallic porphyrins on the aggregate, which occurred during the colloidal asphaltene formation process, through strong acid-base interactions, hydrophobic inclusion, and $\pi-\pi$ stacking intermolecular forces, based on UV-Vis data [17]. Tynan and Yen [18] reported free energy of about 60 $\mathrm{kJ} \mathrm{mol}^{-1}$ generated through the combined interactions of asphaltene-vanadyl porphyrin aggregation, which is much stronger than hydrogen bonds $\left(10-40 \mathrm{~kJ} \mathrm{~mol}^{-1}\right)$. This trapping process is considered irreversible, due to these strong connections formed, and further increases the difficulties of removing metallic porphyrins from asphaltene [15].

\section{n STRUCTURE OF METALLIC PORPHYRINS}

The metallic porphyrins structure of vanadium and nickel have previously been studied to provide a better insight into the chemistry field. Initially, the structures were investigated through UV-Vis spectroscopy, by observing the conjugated moiety. Moreover, the electronic absorptions were predominantly investigated through the $\pi-\pi^{*}$ transition, as $n-\pi^{*}$ transition is unavailable, due to the discrepancy in the symmetry of the $\mathrm{n}$ orbital (on symmetry plane) and $\pi^{*}$ orbital (on antisymmetry plane).
These metallic porphyrins produced highintensity Soret signals at about $400 \mathrm{~nm}$, and also around 500-600 nm, corresponding to $\alpha$ - and $\beta$ - bands from peripheral substituents in the framework [19]. Fig. 2 shows the labelling of $\alpha_{-}^{-}, \beta-, \alpha^{*}, \beta^{*}$ - and meso substituents, and the high signal intensity prompts researchers to use UV-Vis spectroscopy during quantification assessment. However, the concentrations calculated from the UV-Vis spectrum produced showed the absence of approximately half the total quantity, in contrast with the value measured through atomic absorption spectroscopy (AAS) [6]. These reports were observed in crude oil samples obtained from Europe, Russian, and others [20-21]. Therefore, metallic nonporphyrin species were assumed to be present, although none was ever discovered and verified to this day [22].

Through technological development over the years, further chemical analysis using mass spectrometry and X-ray spectroscopy have confirmed the nonexistence of metallic non-porphyrins in crude oils [22]. Therefore, false calculation obtained with UV-Vis spectroscopy was attributed to the postulation stipulating the presence of only one species [6]. This possibility was neglected in previous assessments, owing to variations in electronic structures, and the instigating the consequent dissimilarity in spectra. Moreover, metallic porphyrins have also been identified in the form of alkyl-, oxygenated-, nitrogenated-, and sulfurcontaining porphyrins [22].

Fig. 3 shows some examples of metallic porphyrin structures discovered, while Table 2 demonstrate the Soret-, $\alpha$-, and $\beta$-bands of specific vanadyl forms. Berezin [23] introduced the concept of "Mutual Atomic Effect",

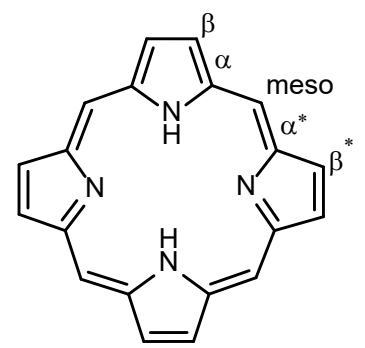

Fig 2. Peripheral substituents location on the porphyrin framework 

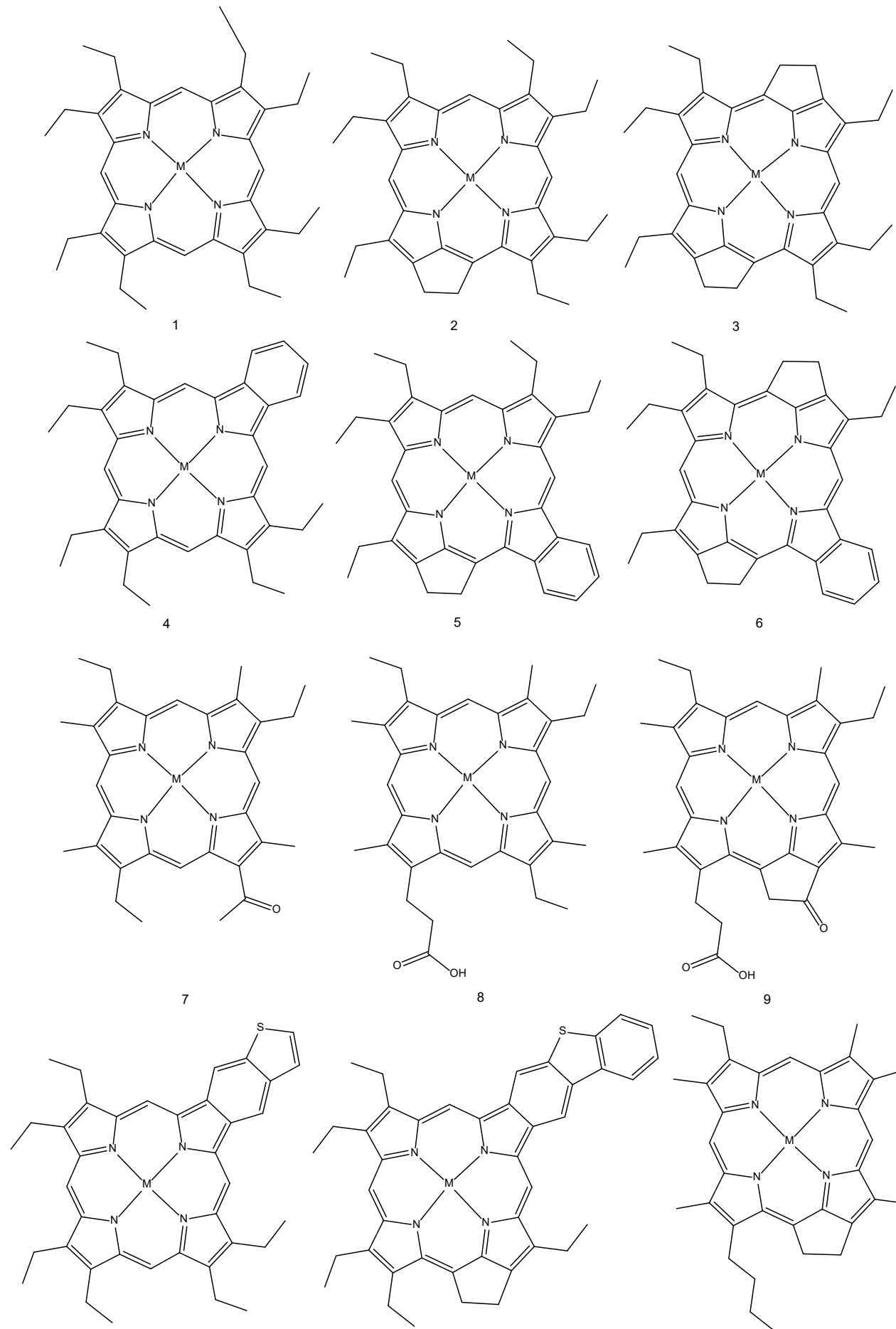

10
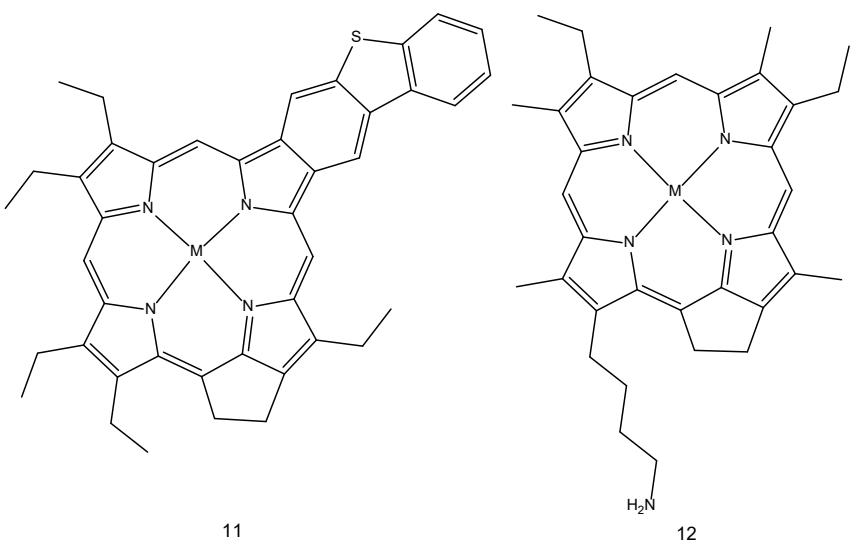

Fig 3. The example of the discovered metallic porphyrins $(\mathrm{M}=\mathrm{Ni}$ or $\mathrm{VO})$

which describes the influence of different peripheral substitution on the electronic distribution and light absorption magnitude, as observed in Fig. 2. This phenomenon instigates a spectral shift and/or higher/ lower extinction coefficient [23]. The dissimilarity in the Soret-, $\alpha$ - or $\beta$-band of each vanadyl-porphyrin caused 
Table 2. Absorption signals of vanadyl-porphyrin derivatives on the UV-Vis spectrum [28]

\begin{tabular}{lccc}
\hline \multirow{2}{*}{ Vanadyl-porphyrins } & \multicolumn{3}{c}{ Wavelength $(\mathrm{nm})$} \\
\cline { 2 - 4 } & Soret band & a-band & $\beta$-band \\
\hline Unmodified & 399 & 559 & 524 \\
ETIO & 407 & 571 & 533 \\
DPEP & 411 & 573 & 533 \\
Benzo-substituted & 414 & 579 & 545 \\
Octaethyl-substituted & 407 & 571 & 533 \\
\hline
\end{tabular}

${ }^{\star}$ Dichloromethane was used as the solvent

the inevitable miss-calculations observed with UV-Vis spectroscopy. In addition, Foster and Cantu [24-25] also reported on the variations in extinction coefficients amongst one another. This was detected with the values for etioporphyrin (ETIO) determined to be four times higher than deoxophylloertythroetioporphyrin (DPEP) derivatives [20]. Moreover, other possible factors implicated in the underestimated calculation comprise the multiple $\pi-\pi$ stacking interactions in asphaltene-metallic porphyrin aggregations. The presence of polycyclic aromatic hydrocarbons potentially influenced poor measurement precision, and consequently interfered with signal intensity, as observed using UV-Vis spectroscopy [26].

Yakubov et al. [27] reported on the UV-Vis spectra modifications observed with porphyrins, after the demetallization reaction. Subsequently, the free porphyrins provided four Q-signals in the visible regions after the removal of central metal ions (either $\mathrm{Ni}^{2+}$ or $\mathrm{VO}^{2+}$ ). These were usually noted as I, II, III, and IV signals [10], and the order is numbered from the longer to shorter wavelength, at $620,565,535$, and $500 \mathrm{~nm}$, respectively. Also, the signals attributed for the conformation and nature of peripheral substitutions possibly existed in six different conformations, including saddle, ruffle, dome, wave on the $\mathrm{x}$-axis, wave on the $\mathrm{y}$-axis, and propeller forms, as shown in Fig. 4 [22].

The limitations of metallic porphyrins characterization through UV-Vis instigated the use of mass spectrometry and Fourier-transform ion cyclotron resonance mass spectrometry. This technique elucidated the correct structure [19,28-30], and about 370 variants were consequently reported. In addition, the vanadylporphyrin alone were classified into 6 categories, including 1. $\mathrm{C}_{\mathrm{n}} \mathrm{H}_{2 \mathrm{n}-\mathrm{y}} \mathrm{N}_{4} \mathrm{VO}(35<\mathrm{n}<60 ; 39<\mathrm{y}<46)$

2. $\mathrm{C}_{\mathrm{n}} \mathrm{H}_{2 \mathrm{n}-\mathrm{y}} \mathrm{N}_{4} \mathrm{VO}_{2}(26<\mathrm{n}<47 ; 29<\mathrm{y}<39)$

3. $\mathrm{C}_{\mathrm{n}} \mathrm{H}_{2 \mathrm{n}-\mathrm{y}} \mathrm{N}_{4} \mathrm{VO}_{3}(26<\mathrm{n}<34 ; 29<\mathrm{y}<39)$

4. $\mathrm{C}_{\mathrm{n}} \mathrm{H}_{2 \mathrm{n}-\mathrm{y}} \mathrm{N}_{4} \mathrm{VO}_{4}(27<\mathrm{n}<37 ; 31<\mathrm{y}<37)$

5. $\mathrm{C}_{\mathrm{n}} \mathrm{H}_{2 \mathrm{n}-\mathrm{y}} \mathrm{N}_{4} \mathrm{VSO}(34<\mathrm{n}<56 ; 37<\mathrm{y}<47)$

6. $\mathrm{C}_{\mathrm{n}} \mathrm{H}_{2 \mathrm{n}-\mathrm{y}} \mathrm{N}_{5} \mathrm{VO}(28<\mathrm{n}<43 ; 26<\mathrm{y}<36)$

Fig. 3 shows the structures of alkyl-, sulfurcontaining and oxygenated-porphyrins, where $\mathrm{M}$ denotes either $\mathrm{VO}^{2+}$ or $\mathrm{Ni}^{2+}$. Particularly, $\mathrm{M}$ at $\mathrm{VO}^{2+}$ yields compound 1-6, which are collectively classified as alkyl porphyrins class $1\left(\mathrm{C}_{\mathrm{n}} \mathrm{H}_{2 \mathrm{n}-\mathrm{y}} \mathrm{N}_{4} \mathrm{VO}\right.$ with $35<\mathrm{n}<60$ and $39<\mathrm{y}<46$ ). In addition, compounds 1,2 , and 3 were infamous as ETIO, DPEP, and Di-DPEP (dicyclicdeoxophylloerythroetioporphyrins), while 4, 5, and 6 comprise rhodo-ETIO (rhodo-etioporphyrins), rhodoDPEP (rhodo-deoxophylloerythroetioporphyrins), and rhodo-Di-DPEP (rhodo-dicylic-deoxophylloerythroetio porphyrins), respectively. Moreover, 7, 8, and 9 are oxygenated-porphyrin derivatives, with 7 belonging to class $2\left(\mathrm{C}_{\mathrm{n}} \mathrm{H}_{2 \mathrm{n}-\mathrm{y}} \mathrm{N}_{4} \mathrm{VO}_{2}\right.$ having $26<\mathrm{n}<47$ and $29<\mathrm{y}<$ 39 ), resulting from the one extra oxygen atom present in the form of a ketone group. Conversely, compound $\mathbf{8}$ is categorized in class $3\left(\mathrm{C}_{\mathrm{n}} \mathrm{H}_{2 \mathrm{n}-\mathrm{y}} \mathrm{N}_{4} \mathrm{VO}_{3}\right.$ with $26<\mathrm{n}<34$ and $29<y<39$ ), due to the two extra oxygen atoms in the form of carboxylic acid. The compound 9 is grouped in class $4\left(\mathrm{C}_{\mathrm{n}} \mathrm{H}_{2 \mathrm{n}-\mathrm{y}} \mathrm{N}_{4} \mathrm{VO}_{4}\right.$ with $27<\mathrm{n}<37$ and $31<\mathrm{y}<$ 37) because of the additional three oxygen atoms, while

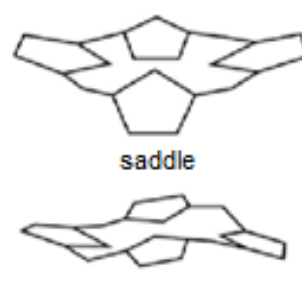

wave on $\mathrm{x}$-axis

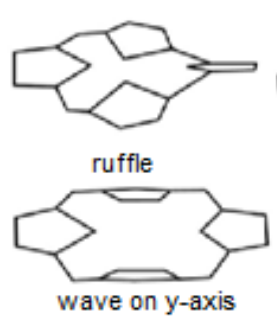

Fig 4. Conformation of metallic porphyrins

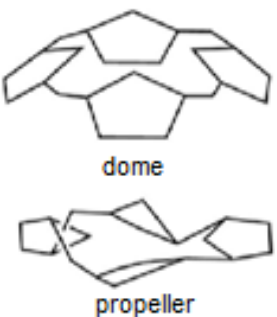

ropeller

Jumina et al. 
10 and 11 represent sulfur-containing porphyrins $\left(\mathrm{C}_{\mathrm{n}} \mathrm{H}_{2 \mathrm{n}}\right.$ ${ }_{\mathrm{y}} \mathrm{N}_{4} \mathrm{VSO}$ with $34<\mathrm{n}<56$ and $37<\mathrm{y}<47$ ), and 12 denotes a nitrogen-containing class $\left(\mathrm{C}_{\mathrm{n}} \mathrm{H}_{2 n-\mathrm{y}} \mathrm{N}_{5} \mathrm{VO}\right.$ with $28<\mathrm{n}<$ 43 and $26<y<36)$.

The metallic porphyrin derivatives have been thoroughly investigated through theoretical and experimental researches. The Density Functional Theory (DFT) computational method has been applied to evaluate the electronic structure of vanadyl-porphyrins present in the crude oil. Furthermore, tests using the varied porphyrin substituent showed the influence of alkyl chains on the solubility of metallic variants in an oily environment. The results also predicted the development of higher reactivity following an increase in the substituent quantity. This output consequently becomes more poisonous after applying catalysts in hydrodemetallization and hydrodesulfurization processes [16].

Garcia-Montoto et al. [9] predicted the three steps of the poisoning mechanism. First is the coke formation from metallic porphyrins on the catalyst surface, which is a rapid reaction with first-order reaction halftime of about a hundred hours. Second, the metallic porphyrins slowly cover the entire surface to ensure gradual activity deactivation. Third, the yields tend to create pore plugging, then facilitate access restriction to the catalyst active site, and consequently prompt a drastic termination of activity [9].

In addition, the product also demonstrated some other disadvantages, in the crude oil. These include influencing the physicochemical properties of petrochemicals, contaminating the desired output, and corroding metallic equipment during the process [6]. Therefore, porphyrin detection and quantification are crucial to select a suitable removal technique.

\section{- DETECTION AND QUANTIFICATION OF METALLIC PORPHYRINS IN CRUDE OILS}

Prior to the detection and quantification processes, several analytical methods have contemporarily been developed to isolate the metallic porphyrins in crude oil samples [31]. This approach is pivotal due to the existence of trace concentration (less than $1.0 \mathrm{~g} \mathrm{~L}^{-1}$ ) in the investigated entity [6]. The matrix crude oil samples tend to vary across sources, and further enhances the difficulty towards establishing a direct and standard detection as well as quantification [26]. Besides, there are a total of three well-known analytical isolation techniques, including Saturate, Aromatic, Resin and Asphaltene (SARA), Soxhlet extraction, and vacuum sublimation method, as shown in Fig. 5 [16].

Particularly, SARA has been identified as the most used approach, resulting from the good ability to separate asphaltene fractions from others, including the saturated, aromatic, and resin fractions [32-34]. This technique is initiated by dissolving the crude oil in dichloromethane solvent, followed by the addition of alumina material, and drying through flowing nitrogen gas [35]. The residue is packed as the stationary phase of the chromatography column and subsequently eluted stepwise using $n$-hexane:cyclohexane 1:1 v/v, $n$ hexane:toluene $7: 3 \mathrm{v} / \mathrm{v}$, carbon tetrachloride:chloroform $7: 3 \mathrm{v} / \mathrm{v}$, and acetonitrile:methanol $1: 1 \mathrm{v} / \mathrm{v}$ to respectively obtain the saturated (A1), aromatic (A2), resin (A3), and asphaltene (A4) fractions of crude oil. Preconcentration of metallic porphyrins using the SARA method has been reported for Venezuela crude oil, Russia Tatarstan crude oil, Kuwait crude oil, Athabasca oil sand, Utah oil sand, China Qingchuan gilsonite oil, Texas shale oil, heavy Eurasian oil, and light East Asian oil [16,36-37].

Marquez et al. [16] adopted the SARA technique while isolating metallic porphyrins from Venezuela crude oil (Table 3 ) to give concentrated vanadium and nickel-porphyrins in resin and asphaltene fractions. Compared to other methods, SARA technology gives satisfying preconcentration of metallic porphyrins which are commonly found only in resin and asphaltene fractions. Zheng et al. [36] also reported a successful preconcentration of metallic porphyrins at 120-550, 50800, 240-640, 21-170, 366-3888, and 257-270 mg kg-1 from Russia Tatarstan crude oil, Kuwait crude oil, Athabasca oil sand, Utah oil sand, China Qingchuan gilsonite oil, and Texas shale oil samples, respectively, which is remarkable. However, the SARA technique is time-consuming and expensive due to a complicated chromatographic solvent composition for each fraction. 


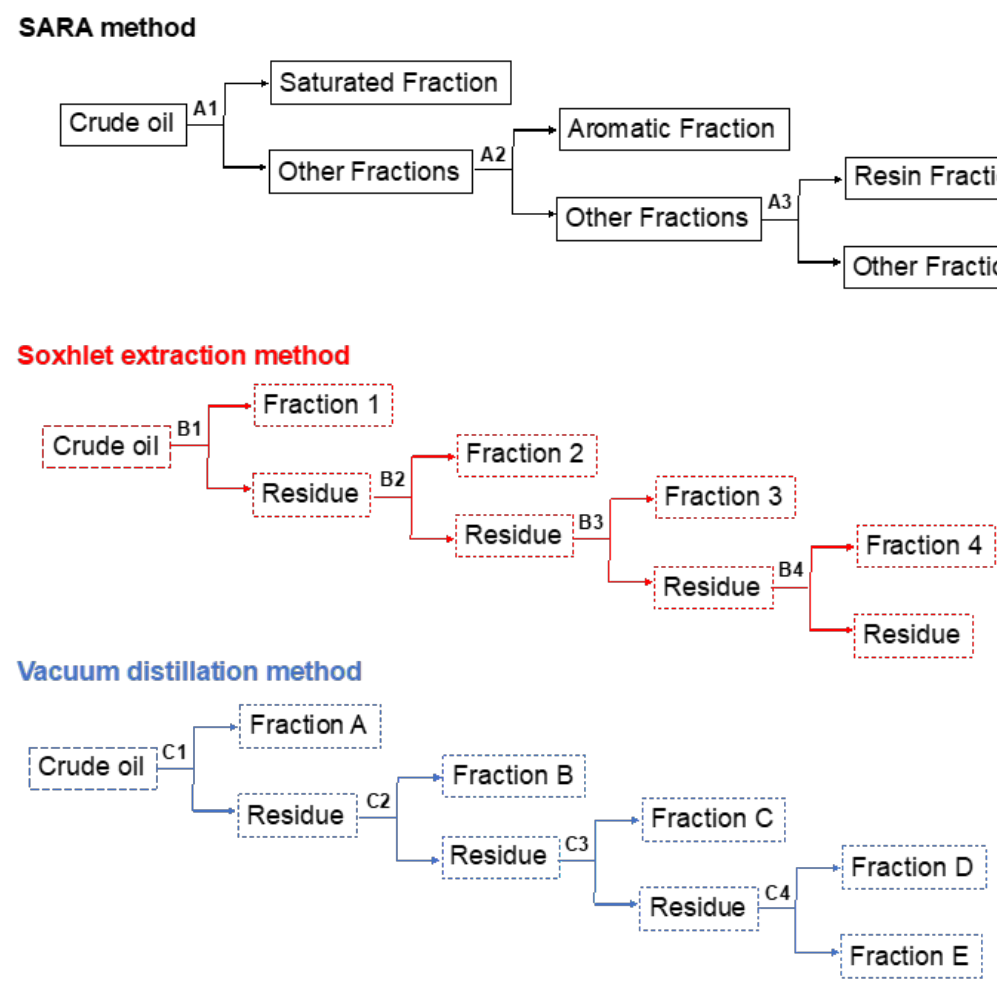

Fig. 5. Isolation of metallic porphyrins from crude oil using SARA, Soxhlet extraction, and vacuum distillation methods

Table 3. The physicochemical properties of the obtained fractions of crude oils for metallic porphyrins from Venezuelan crude oil [16]

\begin{tabular}{|c|c|c|c|c|}
\hline Fraction & Color & Yield (\%) & Vanadium content $\left(\mathrm{mg} \mathrm{kg}^{-1}\right)$ & Nickel content $\left(\mathrm{mg} \mathrm{kg}^{-1}\right)$ \\
\hline \multicolumn{5}{|l|}{ SARA method } \\
\hline Saturated fraction & Pale yellow & 21 & 0 & 0 \\
\hline Aromatic fraction & Yellow & 6 & 0 & 0 \\
\hline Resin fraction & Black & 36 & 900 & 80 \\
\hline Asphaltene fraction & Red wine & 15 & 1,100 & 100 \\
\hline \multicolumn{5}{|c|}{ Soxhlet extraction method } \\
\hline Fraction 1 & Red wine & 8 & 120 & 2 \\
\hline Fraction 2 & Orange & 29 & 75 & 2 \\
\hline Fraction 3 & Brown dark & 49 & 950 & 26 \\
\hline Fraction 4 & Colorless & 11 & 1,060 & 39 \\
\hline \multicolumn{5}{|c|}{ Vacuum sublimation method } \\
\hline Fraction A & Light yellow & 12 & 5 & 34 \\
\hline Fraction B & Orange & 15 & 104 & 14 \\
\hline Fraction C & Dark red & 19 & 226 & 7 \\
\hline Fraction D & Red & 23 & 178 & 6 \\
\hline Fraction E & Black & 29 & 514 & 50 \\
\hline
\end{tabular}

Conversely, Soxhlet extraction method is distinguished as a low-cost and faster isolation method. This process is initiated by mixing the crude oil and alumina material in dichloromethane as the solvent, followed by covering the residue in a Soxhlet extractor with cellulose filter paper. The extraction process required four consecutively used solvents, including acetonitrile, methanol, $n$-heptane, and benzene to obtain 
fractions 1, 2, 3, and 4, respectively. Table 3 shows the existence of metallic porphyrins in all yields from Venezuela crude oil, especially fraction 4, which however contained a lesser amount in contrast with the asphaltene fraction generated through SARA [16]. Additionally, the Soxhlet extraction method employs carcinogenic benzene as the solvent which has been banned for a green and safety process [38]. Kumolo et al. [39] identified the metallic porphyrins in Duri crude oil using the Soxhlet extraction method and it was found that both vanadium and nickel-porphyrins were found in $n$-heptane and aromatic solvents demonstrating low efficiency of the Soxhlet extraction method.

The vacuum distillation method required heating the desired sample under vacuum conditions to ensure crude oil fraction sublimation. Therefore, yields from the asphaltene fraction in SARA served as the feedstock, after drying with flowing nitrogen gas and placing in the vacuum distillation apparatus. Nikolaychuk et al. [40] reported that vacuum distillation required a high temperature $(350-1300 \mathrm{~K})$ depending on the origin of crude oil. Usage of high temperature on the vacuum distillation method was reported for the undesired thermal cracking of crude oil, which is unfavorable [41]. For the Venezuela crude oil samples, the vacuum condition was set at $1.3 \times 10^{-5} \mathrm{~atm}$, a heating temperature from 353 to $513 \mathrm{~K}$, which was gradually increased, and the products were obtained at respective levels (Table 3 ). The obtained fractions from the vacuum distillation method include fraction A (collected at 363-393 K), fraction B (collected at 403-433 K), fraction C (collected at 443-473 $\mathrm{K}$ ), fraction $\mathrm{D}$ (collected at $483-523 \mathrm{~K}$ ), and fraction $\mathrm{E}$ (residue). Table 3 identified this technique as the least useful ascribed to poor preconcentration ability as well as narrow suitability for only volatile compounds [16]. Therefore, the vacuum distillation technique is the most expensive due to the usage of vacuum technology.

Numerous analytical approaches have been adopted during metallic porphyrin detection and quantification [26]. These include gel permeation chromatography, Ultraviolet-Visible (UV-Vis) spectroscopy, inductively coupled plasma-mass spectrometry (ICP-MS), and electron paramagnetic resonance. However, UV-Vis spectroscopy is known to be the simplest with extensive application [31], as observed with the concentration of vanadyl-porphyrins, estimated using the Eq. (2) as follow; Conc. of vanadyl-porphirins $\left(\mathrm{mg} \mathrm{kg}^{-1}\right)=\frac{1.87 \mathrm{~h} \mathrm{~V}}{\mathrm{~m} \mathrm{l}}$

where $\mathrm{h}$ denotes the height of $\alpha$-band at $570-580 \mathrm{~nm}, \mathrm{~V}$ represents the sample volume (dilution factor), $\mathrm{m}$ is the crude oil sample mass, and 1 signifies the cuvette thickness [27].

Reliability of up to $15 \%$ was determined during vanadyl-porphyrin direct quantification using UV-Vis spectroscopy [42]. This analysis technique has low applicability due to the presence of various metallic porphyrins in the sample. Furthermore, the consequent aggregation with the asphaltene fractions lowers the collective absorbance in contrast with the free form [31].

Conversely, gel permeation chromatography reportedly provides metallic porphyrin measurements with better validity [43]. Garcia-Montoto et al. [9] reported a successful quantification using this technique, alongside the addition of HR4 styrenedivinylbenzene as well as $0.5 \% \mathrm{v} / \mathrm{v}$ isopropanol in benzene as the stationary and mobile phase, respectively. Subsequently, the metallic porphyrin yields were separated based on molecule size and concentration before the standard calibration curve is calculated [9]. The preparation and purification processes were technically difficult because of the inability to directly inject crude oil into the apparatus [44]. Moreover, a different porphyrin ligand structure demonstrates varied retention time, which subsequently increases the analysis complexity. Furthermore, some metallic porphyrins tend to be adsorbed on the stationary phase and consequently poison the column used [45].

Electron paramagnetic resonance is potentially adopted in vanadyl-porphyrins. This is due to the presence of one unpaired electron in the $3 \mathrm{~d}$ orbital of $\mathrm{V}^{4+}$ ions [46], which easily resonates in the static magnetic field. In addition, the measurement technique is assumed valid enough because quantification is centered on vanadium atoms and not the porphyrin frameworks as observed with UV-Vis spectroscopy. The precision with this method is remarkable at up to $99.9 \%$ [47]. 
Tynan and Yen [18] reported on the tendency to effectively use electron paramagnetic resonance in the detection of both non-aggregated and aggregated vanadyl-porphyrins. However, the only limitation was impacted by the inability to distinguish the different porphyrin framework types attached to vanadium atoms.

The total intrinsic metallic content was determined through ICP-MS analysis [26]. This required first ashing the crude oil sample for $12 \mathrm{~h}$ at $823 \mathrm{~K}$. Therefore, the output was digested using a mixture of concentrated nitric acid $(75 \% \quad \mathrm{wt} / \mathrm{v})$ : hydrogen peroxide $(30 \% \mathrm{v} / \mathrm{v})$ : concentrated hydrochloric acid (36\% wt $/ \mathrm{v}) 4: 1: 1 \mathrm{v} / \mathrm{v} / \mathrm{v}$ for $24 \mathrm{~h}$. Subsequently, the solution derived was diluted with distilled water before subjecting to the ICP-MS measurement for the quantification of ${ }^{51} \mathrm{~V}$ and ${ }^{60} \mathrm{Ni}$. This assessment procedure was analyzed for precision and the results showed similarity with the electron paramagnetic resonance method because measurements were based on the metal elements.

\section{- REMOVAL OF METALLIC PORPHYRINS FROM CRUDE OILS}

Currently, there are numbers of separation techniques established to ensure metallic porphyrin removal from crude oils [31]. These include solvent extraction, chelation with chemical agents, supercritical water extraction, and hydrodemetallization processes [12]. Solvent extraction is a well-known technique for metallic porphyrins removal from crude oil because of its convenient operation condition. Particularly, the solvent extraction technique is aimed at releasing the metal ions from the metallic porphyrins complex, and polar solvents in the form of $\mathrm{N}, \mathrm{N}$-dimethylformamide, acetonitrile, isopropanol, and methanol have frequently been applied [48]. Moreover, a small amount of sulfonic or sulfuric acid is sometimes added to ensure the protonation of nitrogen atoms present in porphyrin and to further weaken the metal-porphyrin bonds. This removal technique is, unfortunately, suitable for only crude oil with low resinasphaltene fraction. Also, the high viscosity instils difficulty for the diffusion process to reach an equilibrium state, and the porphyrin removal process ultimately becomes also time-consuming [31]. As an example, the removal of vanadium-porphyrins from heavy oil using solvent extraction technique only gave $45 \%$ removal at $303 \mathrm{~K}$ [49]. Therefore, larger solvent quantity and energy are required to improve feasibility, which is unfavorable.

The principle of metal chelation with chemical agents involves the use of suitable chemical agents characterized by a higher complexation tendency towards vanadium and nickel, followed by the possible release from the porphyrin framework [50-51]. A study by Mokhtari and Pourabdollah [52] showed the vanadylporphyrin extraction process, using calix[4]arene, a nano-basket dicarboxylic acid. This compound and its derivatives demonstrate outstanding discrimination capacity in line with metal ions, due to the strong complexation energy resulting from electrostatic interactions and size exclusions [53-58]. Remarkably, about $96 \%$ of the vanadium is reportedly removed over a 90 min operation period [52]. Shang et al. [59] reported a shorter removal time for vanadium- and nickelporphyrins by 85 and $83 \%$, respectively, while using a sulfonyl acid chemical in a microwave electric field set at 600 Watts for $3 \mathrm{~min}$. The high removal percentage was attributed to the porphyrin framework deformation observed during microwave irradiation, and further facilitates the demetallization reaction [60].

Supercritical extraction is advanced technology using supercritical fluid as the extracting solvent at above critical temperature and pressure. Mandal et al. [61] investigated the supercritical water extraction of nickel and vanadium from heavy oils, under conditions operated at 22.1 MPa, $763 \mathrm{~K}$, and without a catalyst. Therefore, about $80 \%$ of the metallic porphyrins were respectively removed. Based on kinetic and thermodynamic studies, hydroxyl and hydrogen radicals were proposed to play a pivotal role in the demetallization process. The attachment to vanadium and nickel occurs in the hydride and hydroxyl forms, and consequently weaken the metalporphyrin bonds. Conversely, these radicals also attacked porphyrin rings, and therefore instigates conformational changes, as well as weakens the chelating capacity towards both vanadyl and nickel ions [62]. However, supercritical extraction technology is not economically feasible due to its requirement for high temperature and 
pressure.

In addition, several demetallization procedures have been exploited over the past several years, including the oxidative [63], bio- [64-65], electrolytic [66], ultrasonic [67], and photo-demetallation [68]. These have however been recognized as ineffective resulting from the intrinsic tendency to change the crude oil physicochemical properties, which is unfavorable. Oxidative demetallation of crude oil was studied by Gould [63], however, a significant change in the physicochemical properties of crude oil happened. Bio-demetallation offers up to $55 \%$ of vanadyl-porphyrins [64] and $11 \%$ of nickel-porphyrins [65] demetallization percentage from crude oil after $24 \mathrm{~h}$ process at $328 \mathrm{~K}$ due to metabolic inhibition of microorganism in the presence of a large amount of vanadyl-porphyrins. The tolerance level of microorganisms for bio-demetallation is very low, around $20 \mathrm{mg} \mathrm{kg} \mathrm{g}^{-1}$ vanadyl-porphyrins in crude oil making bio-demetallation technology is not applicable for commercial process.

Electrolytic-demetallation was reported for Orinoco Belt crude oil with $73 \%$ demetallization percentage at 0.01 A $\mathrm{cm}^{-2}$ current density, however, this technology is energy-consuming [66]. Ultrasonic-demetallation was reported for crude oil at $423 \mathrm{~K}$ in 1-methyl naphthalene solvent yielding 35\% demetallation percentage, however, a heavy part of crude oil was decoagulated and depolymerized into maltene fraction [67]. Meanwhile, a photo-demetallation process in a liquid-liquid extraction reactor was reported for metallic porphyrins removal from crude oil under ultraviolet irradiation for $10 \mathrm{~h}$. This technology exhibits high demetallation percentages, i.e. 75 and $96 \%$ for commercial light oil and light gas oil. Unfortunately, some aromatic parts of crude oil were also decomposed thus the physicochemical properties of the crude oil were changed [68].

Comparably, hydrodemetallization processes are highly selective targets for metallic porphyrins which could be applied for a wide coverage of crude oil samples [69]. Despite the propensity to hydrogenate the hydrocarbon parts, the products obtained remain significantly satisfying [70]. The demetallation percentage is around $60-90 \%$ using metal oxides in the aluminium oxide or sodium aluminium silicate as the catalyst materials in the hydrodemetallization process. As an example, as much as $71 \%$ demetallation percentage was achieved for Lago crude oil using hydrodemetalation process at $739 \mathrm{~K}$ using $3.5 \% \mathrm{CoO}$ and $10 \% \mathrm{MoO}_{3}$ catalyst at $\mathrm{Al}_{2} \mathrm{O}_{3}$ support. On the other hand, vanadyl- and nickel-porphyrins were successfully removed in 85 and $68 \%$, respectively, from European crude oil at $683 \mathrm{~K}$ [7172]. Unfortunately, some of the drawbacks experienced during hydrodemetallization include large heat and hydrogen gas consumption, which leads to an elevated operational cost. Furthermore, it is possible to gradually deposit vanadium or nickel metals on the used catalyst, and consequently lower catalyst activity by increasing operation time [12].

Lee et al. [73] successfully converted the vanadylporphyrins present in the asphaltene fractions of crude oil to vanadium(III) sulfide $\left(\mathrm{V}_{2} \mathrm{~S}_{3}\right)$ before the potential application as a hydrocracking catalyst. Therefore, the cracking phase ensued at $693 \mathrm{~K}$ and $11.0 \mathrm{MPa} \mathrm{H}_{2}$ to obtain middle distillates, naphtha, gas, vacuum gas oils, and coke fractions in $30 \%$ yield. The strategy devised in this study is significantly useful while the asphaltene fraction during a suitable recycling process. This outcome is attributed to the activity of vanadium as a catalyst material. Langeslay et al. [74] also acknowledged the moderate catalytic activity of vanadium sulfide during the hydrodesulfurization of thiophene, hydrodenitrogenation, and hydrogenation of pyridine and toluene, respectively. This technology significantly influences the removal of metallic porphyrins from crude oils and the consequent utility as active catalyst materials during petrochemical processing.

\section{- CONCLUSION}

The metallic porphyrins present in crude oil samples originate from evolution reactions involving chlorophyll and heme compounds. In addition, isolation and purification processes were followed by characterization using UV-Vis spectroscopy and Fourier transform ion cyclotron resonance mass spectrometry. The results showed a propensity to distinguish alkyl-, oxygen-, nitrogen-, and sulfur-containing porphyrins. Also, a total of six vanadyl classes have been discovered, 
including $\mathrm{C}_{\mathrm{n}} \mathrm{H}_{2 \mathrm{n}-\mathrm{y}} \mathrm{N}_{4} \mathrm{VO}, \mathrm{C}_{\mathrm{n}} \mathrm{H}_{2 \mathrm{n}-\mathrm{y}} \mathrm{N}_{4} \mathrm{VO}_{2}, \mathrm{C}_{\mathrm{n}} \mathrm{H}_{2 \mathrm{n}-\mathrm{y}} \mathrm{N}_{4} \mathrm{VO}_{3}$, $\mathrm{C}_{\mathrm{n}} \mathrm{H}_{2 \mathrm{n}-\mathrm{y}} \mathrm{N}_{4} \mathrm{VO}_{4}, \mathrm{C}_{\mathrm{n}} \mathrm{H}_{2 \mathrm{n}-\mathrm{y}} \mathrm{N}_{4} \mathrm{VSO}$, and $\mathrm{C}_{\mathrm{n}} \mathrm{H}_{2 \mathrm{n}-\mathrm{y}} \mathrm{N}_{5} \mathrm{VO}$ types. The several analytical methods established to detect and quantify metallic porphyrins comprise gel permeation chromatography, UV-Vis spectroscopy, ICP-MS analysis, and electron paramagnetic resonance. Moreover, the porphyrin presence is undesirable, as observed with the negative effects on the petrochemical's physicochemical properties, used catalyst deactivation, contamination of desired products, and the corrosion of metal equipment during processing. Therefore, it is essential to remove the metallic porphyrins through solvent extraction, supercritical water extraction, chelation with chemical agents, or hydrodemetallization processes. Each removal technology has its own advantages and disadvantages. Solvent extraction is the most applied technology today, however, this technique is only suitable for crude oil with a low resin-asphaltene amount. Hydrodemetallization offers a promising way due to its wide application and high selectivity, however, hydrodemetallization is inevitably high-cost technology. Further research and development for these technologies still open to establishing an efficient technology for the removal of metallic porphyrins from crude oil.

\section{- ACKNOWLEDGMENTS}

The financial support from RISPRO LPDP Kemenkeu RI under contract number PRJ-48/LPDP/2020 for budget year 2020-2022 is deeply acknowledged. Technical and material supports from PT. Pertamina (Persero) are also greatly appreciated.

\section{- REFERENCES}

[1] Wahyuningsih, T.D., and Kurniawan, Y.S., 2017, Green synthesis of some novel dioxolane compounds from Indonesian essential oils as potential biogrease, AIP Conf. Proc., 1823, 020081.

[2] Jumina, Yasodhara, Y., Triono, S., Kurniawan, Y.S., Priastomo, Y., Chawla, H.M., and Kumar, N., 2020, Preparation and evaluation of a-cellulose based new heterogeneous catalyst for production of biodiesel, $J$. Appl. Polym. Sci., 138 (2), 49658.

[3] Lang, K., and Auer, B.R., 2020, The economic and financial properties of crude oil: A review, North Am. J. Econ. Finance, 52, 100914.

[4] Wahyuningsih, T.D., and Kurniawan, Y.S., 2020, Synthesis of dioxo-dioxane and dioxo-dioxepane ethyl oleate derivatives as bio-lubricant base stocks, Indones. J. Chem., 20 (3), 503-509.

[5] Ederington, L.H., Fernando, C.S., Hoelscher, S.A., Lee, T.K., and Linn, S.C., 2019, A review of the evidence on the relation between crude oil prices and petroleum product prices, J. Commod. Mark., 13, 1-15.

[6] Furimsky, E., 2016, On exclusivity of vanadium and nickel porphyrins in crude oil, Energy Fuels, 30 (11), 9978-9980.

[7] Munoz, G., Gunessee, B.K., Bégué, D., Bouyssiere, B., Baraille, I., Vallverdu, G., and Silva, H.S., 2019, Redox activity of nickel and vanadium porphyrins: A possible mechanism behind petroleum genesis and maturation?, RSV Adv., 9 (17), 9509-9516.

[8] Corma, A., Corresa, E., Mathieu, Y., Sauvanaud, L., Al-Bogami, S., Al-Ghrami, M.S., and Bourane, A., 2017, Crude oil to chemicals: Light olefins from crude oil, Catal. Sci. Technol., 7, 12-46.

[9] Garcia-Montoto, V.G., Verdier, S., Maroun, Z., Egeberg, R., Tiedje, J.L., Sandersen, S., Zeuthen, P., and Bouyssiere, B., 2020, Understanding the removal of $\mathrm{V}, \mathrm{Ni}$ and $\mathrm{S}$ in crude oil atmospheric residue hydrodemetallization and hydrodesulfurization, Fuel Process. Technol., 201, 106341.

[10] Liu, T., Lu, J., Zhao, X., Zhou, Y., Wei, Q., Xu, C., Zhang, Y., Ding, S., Zhang, T., Tao, X., Ju, L., and Shi, Q., 2015, Distribution of vanadium compounds in petroleum vacuum residuum and their transformations in hydrodemetallization, Energy Fuels, 29 (4), 2089-2096.

[11] Argyle, M.D., and Bartholomew, C.H., 2015, Heterogeneous catalyst deactivation and regeneration: A review, Catalysts, 5 (1), 145-269.

[12] Jenifer, A.C., Sharon, P., Prakash, A., and Sande, P.C., 2015, A review of the unconventional methods used for the demetallization of petroleum fractions 
over the past decade, Energy Fuels, 29 (12), 7743-7752.

[13] Treibs, A., 1934, Chlorophyll and haemin derivatives in bituminous rock, petroleum, mineral waxes and asphalts, Justus Liebigs Ann. Chem., 510 (1), 42-62.

[14] Treibs, A., 1936, Chlorophyll and hemin derivatives in organic materials, Angew. Chem., 49 (38), 682-686.

[15] Castillo, J., and Vargas, V., 2016, Metal porphyrin occlusion: Adsorption during asphaltene aggregation, Pet. Sci. Technol., 34 (10) 873-879.

[16] Espinosa, M., Pacheco, U.S., Leyte, F., and Ocampo, R., 2014, Separation and identification of porphyrin biomarkers from a heavy crude oil Zaap-1 offshore well, Sonda de Campeche, Mexico, J. Porphyr. Phtalocyanines, 18 (7), 542-551.

[17] Silva, H.S., Alfarra, A., Vallverdu, G., Begue, D., Bouyssiere, B., and Baraille, I., 2019, Asphaltene aggregation studied by molecular dynamic simulations: Role of the molecular architecture and solvents on the supramolecular or colloidal behavior, Petrol. Sci., 16, 669-684.

[18] Tynan, E.C., and Yen, T.F., 1969, Association of vanadium chelates in petroleum asphaltenes as studied by ESR, Fuel, 43, 191-208.

[19] Liu, H., Mu, J., Wang, Z., Ji, S., Shi, Q., Guo, A., Chen, $\mathrm{K}$., and $\mathrm{Lu}, \mathrm{J} ., 2015$, Characterization of vanadyl and nickel porphyrins enriched from heavy residues by positive-ion electrospray ionization FT-ICR mass spectrometry, Energy Fuels, 29 (8), 4803-4813.

[20] Glebovskaya, E., and Volkenshtein, M., 1948, Spectra of porphyrins in petroleums and bitumens, J. Gen. Chem., 18, 1440.

[21] Skinner, D.A., 1952, Chemical state of vanadium in Santa Maria Valley crude oil, Ind. Eng. Chem., 44 (5), 1159-1165.

[22] Qian, K., Fredriksen, T.R., Mennito, A.S., Zhang, Y., Harper, M.R., Merchant, S., Kushnerick, J.D., Rytting, B.M., and Kilpatrick, P.K., 2019, Evidence of naturally-occurring vanadyl porphyrins containing multiple S and O atoms, Fuel, 239, 1258-1264.

[23] Berezin, B.D.J., 1999, Mutual atomic effect in porphyrin molecules and its manifestation in their structure and electronic absorption spectra, J. Appl. Spectrosc., 66 (4), 521-527.
[24] Foster, N.S., Day, J.W., Filby, R.H., Alford, A., and Rogers, D., 2002, The role of Na-montmorillonite in the evolution of copper, nickel, and vanadyl geoporphyrins during diagenesis, Org. Geochem., 33 (8), 907-919.

[25] Cantú, R., Stencel, J.R., Czernuszewicz, R.S., Jaffé, P.R., and Lash, T.D., 2000, Surfactant-enhanced partitioning of nickel and vanadyl deoxophylloerythroetioporphyrins from crude oil into water and their analysis using surfaceenhanced resonance Raman spectroscopy, Environ. Sci. Technol., 34, 192-198.

[26] Sugiyama, I., and Williams-Jones, A.E., 2018, An approach to determining nickel, vanadium and other metal concentrations in crude oil, Anal. Chim. Acta, 1002, 18-25.

[27] Yakubov, M.R., Milordov, D.V., Yakubova, S.G., Borisov, D.N., Gryaznov, P.I., and Usmanova, G.S., 2015, Sulfuric acid assisted extraction and fractionation of porphyrins from heavy petroleum residuals with a high content of vanadium and nickel, Pet. Sci. Technol., 33 (9), 992-998.

[28] Banda-Cruz, E.E., Padron-Ortega, S.I., GallardoRivas, N.V., Rivera-Armenta, J.L., Paramo-Garcia, U., Zavala, N.P.D., and Mendoza-Martinez, A.M., 2016, Crude oil UV spectroscopy and light scattering characterization, Petrol. Sci. Technol., 34 (8), 732-738.

[29] Zhang, Y., Schulz, F., Rytting, B.M., Walters, C.C., Kaiser, K., Metz, J.N., Harper, M.R., Merchant, S.S., Mennito, A.S., Qian, K., Kushnerick, J.D., Kilpatrick, P.K., and Gross, L., 2019, Elucidating the geometric substitution of petroporphyrins by spectroscopic analysis and atomic force microscopy molecular imaging, Energy Fuels, 33 (7), 6088-6097.

[30] Gao, Y.Y., Shen, B.X., and Liu, J.C., 2012, The structure identification of vanadium porphyrins in Venezuela crude oil, Energ. Sources Part A, 34, 2260-2267.

[31] Milordov, D.V., Usmanova, G.S., Yakubov, M.R., Yakubova, S.G., and Romanov, G.V, 2013, Comparative analysis of extractive methods of porphyrin separation from heavy oil asphaltenes, 
Chem. Technol. Fuels Oils, 49 (3), 232-238.

[32] Munawar, Aditiawati, P., and Astuti, D.I., 2012, Sequential isolation of saturated, aromatic, resinic, and asphaltic fractions degrading bacteria from oil contaminated soil in South Sumatera, Makara J. Sci., 16 (1), 58-64.

[33] Ashoori, S., Sharifi, M., Masoumi, M., and Salehi, M.M., 2017, The relationship between SARA fractions and crude oil stability, Egypt. J. Pet., 26 (1), 209-213.

[34] Musin, L.I., Foss, L.E., Shabalin, K.V., Nagornova, O.A., Borisova, Y.Y., Borisov, D.N., and Yakubov, M.R., 2020, Simple methods for the separation of various subfractions from coal and petroleum asphaltenes, Energy Fuels, 34 (6), 6523-6543.

[35] Rakhmatullin, I., Efimov, S., Tyurin, V., Gafurov, M., Al-Muntaser, A., Varfolomeev, M., and Klochkov, V., 2020, Qualitative and quantitative analysis of heavy crude oil samples and their SARA fractions with ${ }^{13} \mathrm{C}$ nuclear magnetic resonance, Processes, 8 (8), 995.

[36] Zheng, F., Shi, Q., Vallverdu, G.S., Giusti, P., and Bouyssiere, B., 2020, Fractionation and characterization of petroleum asphaltene: Focus on metalopetroleomis, Processes, 8 (11), 1504.

[37] Farmani, Z., and Schrader, W., 2019, A detailed look at the saturate fractions of different crude oils using direct analysis by ultrahigh resolution mass spectrometry (UHRMS), Energies, 12 (18), 3455.

[38] Kurniawan, Y.S., Priyangga, K.T.A., Krisbiantoro, P.A., and Imawan, A.C., 2021, Green chemistry influences in organic synthesis: A review, $J$. Multidiscip. Appl. Nat. Sci., 1, 1-12.

[39] Kumolo, S.T., Yulizar, Y., Haerudin, H., Kurniawaty, I., and Apriandanu, D.O.B., 2019, Identification of metal porphyrins in Duri crude oil, IOP Conf. Ser.: Mater. Sci. Eng., 496, 012038.

[40] Nikolaychuk, E., Veli, A., Stratiev, D., Shishkova, I., Burilkova, A., Tamahkyarova, E., Mitkova, M., and Yordanov, D., 2018, Physical vacuum distillation and high temperature simulated distillation of residual oils from different origin, Int. J. Oil, Gas Coal Technol., 17 (2), 208-221.
[41] Elayane, J., Bchitou, R., and Bouhaouss, A., 2017, Study of the thermal cracking during the vacuum distillation of atmospheric residue of crude oil, Sci. Stud. Cercet. Stiint.: Chim. Ing. Chim., Biotehnol., Ind. Aliment. (Univ. Bacau), 18 (1), 61-71.

[42] Zhao, X., Liu, Y., Xu, C., Yan, Y., Zhang, Y., Zhao, S., Chung, K., Gray, M.R., and Shi, Q., 2013, Separation and characterization of vanadyl porphyrins in Venezuela Orinoco heavy crude oil, Energy Fuels, 27 (6), 2874-2882.

[43] Maryutina, T.A., and Timerbaev, A.R., 2017, Metal speciation analysis of petroleum: Myth or reality?, Anal. Chim. Acta, 991, 1-8.

[44] Putman, J.C., Rowland, S.M., Corilo, Y.E., and McKenna, A.M., 2014, Chromatographic enrichment and subsequent separation of nickel and vanadyl porphyrins from natural seeps and molecular characterization by positive electrospray ionization FT-ICR mass spectrometry, Anal. Chem., 86 (21), 10708-10715.

[45] Mironov, N.A., Sinyashin, K.O., Abilova, G.R., Tazeeva, E.G., Milordov, D.V., Yakubova, S.G., Borisov, D.N., Gryaznov, P.I., Borisova, Y.Y., and Yakubov, M.R., 2017, Chromatographic isolation of vanadyl porphyrins from heavy oil resins, Russ. Chem. Bull., 66 (8), 1450-1455.

[46] Biktagirov, T.B., Gafurov, M.R., Volodin, M.A., Mamin, G.V., Rodionov, A.A., Izotov, V.V., Vakhin, A.V., Isakov, D.R., and Orlinskii, S.B., 2014, Electron paramagnetic resonance study of rotational mobility of vanadyl porphyrin complexes in crude oil asphaltenes: Probing the effect of thermal treatment of heavy oils, Energy Fuels, 28 (10), 6683-6687.

[47] Gafurov, M.R., Volodin, M.A., Rodionov, A.A., Sorokina, A.T., Dolomatov, M.Y., Petrov, A.V., Vakhin, A.V., Mamin, G.V., and Orlinskii, S.B., 2018, EPR study of spectra transformations of the intrinsic vanadyl-porphyrin complexes in heavy crude oils with temperature to probe the asphaltenes' aggregation, J. Petrol. Sci. Eng., 166, 363-368. 
[48] Yakubov, M.R., Milordov, D.V., Yakubova, S.G., Borisov, D.N., Gryaznov, P.I., Mironov, N.A., Abilova, G.R., Borisova, Y.Y., and Tazeeva, E.G., 2016, Features of the composition of vanadyl porphyrins in the crude extract of asphaltenes of heavy oil with high vanadium content, Pet. Sci. Technol., 34 (2), 177-183.

[49] Salleh, N.F., Ishak, N., Ruslan, M.S.H., Mandal, P.C., and Yusup, S., 2018, Fundamental studies on extraction of vanadyl oxide tetraphenyl porphyrin (VO TPP) presence in heavy oil model using toluene assisted ionic liquids, IOP Conf. Ser.: Mater. Sci. Eng., 458, 012069.

[50] Tahoun, M., Gee, C.T., McCoy, V.E., Sander, P.M., and Muller, C.E., 2021, Chemistry porphyrins in fossil plants and animals, RSC Adv., 11, 7552-7563.

[51] Xili, C., Minghuan, S., and Bengao, L., 2010, Effect and mechanism research of removing nickel and vanadium porphyrins from model oil by chemical agent, Pet. Process. Petrochem., 41 (9), 19-22.

[52] Mokhtari, B., and Pourabdollah, K., 2012, Extraction of vanadyl porphyrins in crude oil by inclusion dispersive liquid-liquid microextraction and nanobasket of calixarene, J. Inclusion Phenom. Macrocyclic Chem., 74 (1), 183-189.

[53] Kurniawan, Y.S., Sathuluri, R.R., Iwasaki, W., Morisada, S., Kawakita, H., Ohto, K., Miyazaki, M., and Jumina, 2018, Microfluidic reactor for $\mathrm{Pb}$ (II) ion extraction and removal with amide derivative of calix[4]arene supported by spectroscopic studies, Microchem. J., 142, 377-384.

[54] Sathuluri, R.R., Kurniawan, Y.S., Kim, J.Y., Maeki, M., Iwasaki, W., Morisada, S., Kawakita, H., Miyazaki, M., and Ohto, K., 2018, Droplet-based microreactor system for stepwise recovery of precious metal ions from real metal waste with calix[4]arene derivatives, Sep. Sci. Technol., 53 (8), 1261-1272.

[55] Kurniawan, Y.S., Sathuluri, R.R., Ohto, K., Iwasaki, W., Kawakita, H., Morisada, S., Miyazaki, M., and Jumina, 2019, A rapid and efficient lithium-ion recovery from seawater with tripropyl-monoacetic acid calix[4]arene derivative employing droplet- based microfluidic reactor system, Sep. Purif. Technol., 211, 925-934.

[56] Murphy, P., Dalgarno, S.J., and Paterson, M.J., 2016, Transition metal complexes of calix[4]arene: Theoretical investigations into small guest binding within the host cavity, J. Phys. Chem. A, 120 (5), 824-839.

[57] Kurniawan, Y.S., Ryu, M., Sathuluri, R.R., Iwasaki, W., Morisada, S., Kawakita, H., Ohto, K., Maeki, M., Miyazaki, M., and Jumina, 2019, Separation of $\mathrm{Pb}$ (II) ion with tetraacetic acid derivative of calix[4]arene by using droplet-based microreactor system, Indones. J. Chem., 19 (2), 368-375.

[58] Jumina, Priastomo, Y., Setiawan, H.R., Mutmainah, Kurniawan, Y.S., and Ohto, K., 2020, Simultaneous removal of lead(II), chromium(III), and copper(II) heavy metal ions through an adsorption process using C-phenylcalix[4]pyrogallolarene material, $J$. Environ. Chem. Eng., 8 (4), 103971.

[59] Shang, H., Liu, Y., Shi, J.C., Shi, Q., and Zhang, W.H., 2016, Microwave-assisted nickel and vanadium removal from crude oil, Fuel Process. Technol., 142, 250-257.

[60] Li, Y., Shang, H., Zhang, Q., Elabyouki, M., and Zhang, W., 2020, Theoretical study of the structure and properties of $\mathrm{Ni} / \mathrm{V}$ porphyrins under microwave electric field: A DFT study, Fuel, 278, 118305.

[61] Mandal, P.C., Goto, M., and Sasaki, M., 2014, Removal of nickel and vanadium from heavy oils using supercritical water, J. Jpn. Pet. Inst., 57 (1), 18-28.

[62] Mandal, P.C., Wahyudiono, Sasaki, M., and Goto, M., 2012, Non-catalytic vanadium removal from vanadyl etioporphyrin (VO-EP) using a mixed solvent of supercritical water and toluene: A kinetic study, Fuel, 92 (1), 288-294.

[63] Gould, K.A., 1980, Oxidative demetallization of petroleum asphaltenes and residua, Fuel, 59 (10), 733-736.

[64] Salehizadeh, H., Mousavi, M., Hatamipour, S., and Kermanshahi, K., 2007, Microbial demetallization of crude oil using Aspergillus sp.: Vanadium oxide 
octaethyl porphyrin (VOOEP) as a model of metallic porphyrins, Iran. J. Biotechnol., 5 (4), 226-231.

[65] Dedeles, G.R., Abe, A., Saito, K., Asano, K., Saito, K., Yokota, A., and Tomita, F., 2000, Microbial demetallization of crude oil: Nickel protoporphyrin disodium as a model organo-metallic substrate, $J$. Biosci. Bioeng., 90 (5), 515-521.

[66] Ovalles, C., Rojas, I., Acevedo, S., Escobar, G., Jorge, G., Gutierrez, L.B., Rincon, A., and Scharifker, B., 1996, Upgrading of Orinoco Belt crude oil and its fractions by an electrochemical system in the presence of protonating agents, Fuel Process. Technol., 48 (2), 159-172.

[67] Sakanishi, K., Yamashita, N., Whitehurst, D.D., and Mochida, I., 1998, Depolymerization and demetallation treatments of asphaltene in vacuum residue, Catal. Today, 43 (3-4), 241-247.

[68] Reyes, D.J.K., de Montellano, A.G.S.O., Tzab, R.A.T., Oskam, G., and Gil, J.J.A., 2014, Effects of UV-Vis irradiation on vanadium etioporphyrins extracted from crude oil and the role of nanostructured titania, Int. J. Photoenergy, 2014, 401239.

[69] Nguyen, M.T., Nguyen, D.L.T., Xia, C., Nguyen, T.B., Shokouhimehr, M., Sana, S.S., Grace, A.N., Aghbashlo, M., Tabatabaei, M., Sonne, C., Kim, S.Y., Lam, S.S., and Le, Q.V., 2021, Recent advances in asphaltene transformation in heavy oil hydroprocessing: Progress, challenges, and future perspectives, Fuel Process. Technol., 213, 106681.

[70] Kohli, K., Prajapati, R., Maity, S.K., Sau, M., and Sharma, B.K., 2019, Deactivation of a hydrotreating catalyst during hydroprocessing of synthetic crude by metal bearing compounds, Fuel, 243, 579-589.

[71] Ongarbayev, Y., Oteuli, S., Tileuberdi, Y., Maldybaev, G., and Nurzhanova, S., 2019, Demetallization and desulfurization of heavy oil residues by adsorbents, Pet. Sci. Technol., 37 (9), 1045-1052.

[72] Magomedov, R.N., Popova, A.Z., Maryutina, T.A., Kadiev, K.M., and Khadzhiev, S.N., 2015, Current status and prospects of demetallization of heavy petroleum feedstock (Review), Petrol. Chem., 55, 423-443.

[73] Lee, D., Kim, K.D., and Lee, Y.K., 2020, Conversion of $\mathrm{V}$-porphyrin in asphaltenes into $\mathrm{V}_{2} \mathrm{~S}_{3}$ as an active catalyst for slurry phase hydrocracking of vacuum residue, Fuel, 263, 116620.

[74] Langeslay, R.R., Kaphan, D.M., Marshall, C.L., Stair, P.C., Sattelberger, A.P., and Delferro, M., 2019, Catalytic applications of vanadium: A mechanistic perspective, Chem. Rev., 119 (4), 21282191. 